\title{
Artigos
}

0

\section{ACCESO Y CALIDAD DEL EMPLEO DE LA INMIGRACIÓN RECIENTE EN URUGUAY}

\author{
Access and quality of employment of recent immigration in Uruguay
}

\author{
Victoria Prieto ${ }^{7}$ \\ Sofía Robaina ${ }^{2}$ \\ Martín Koolhaas ${ }^{3}$
}

\begin{abstract}
Resumen. Este artículo analiza las características de acceso y calidad de la inserción laboral de los inmigrantes extranjeros llegados a Uruguay entre 2007 y 2015. Los desempeños de los inmigrantes se comparan con los de la población nativa no migrante y retornada, primero de forma bivariada, luego mediante la inclusión de la condición migratoria en la estimación de modelos logísticos binomiales de la probabilidad de empleo, informalidad y sobrecalificación. La fuente empleada corresponde a las Encuestas Continuas de Hogares del período 2012 - 2015. Los resultados muestran una desventaja sistemática en el acceso al empleo de la población extranjera, y mayor riesgo de sobrecalificación y de informalidad entre los ocupados del mismo origen. Dentro de los extranjeros las mujeres tienen menores chances de insertarse en el mercado de trabajo pero no se encuentra un efecto negativo de la doble condición mujer-inmigrante en los indicadores de calidad del empleo. Si bien el tiempo de asentamiento mitiga el efecto adverso de la condición inmigratoria sobre el empleo, la informalidad y sobrecalificación, éste no desaparece entre los inmigrantes más antiguos.
\end{abstract}

Palabras claves: inmigración, retorno, sobrecalificación, desempleo, informalidad.

1 Programa de Población de la Facultad de Ciencias Sociales, Universidad de la República. Montevideu, Uruguay.

2 Programa de Población de la Facultad de Ciencias Sociales, Universidad de la República. Montevideu, Uruguay.

3 Programa de Población de la Facultad de Ciencias Sociales, Universidad de la República. Montevideu, Uruguay. 


\begin{abstract}
This article analyzes the characteristics of access and quality of employment of foreign immigrants arrived in Uruguay between 2007 and 2015. We compare immigrants' performance to that of the non-migrant native-born and returnees, first using bivariate analysis, then by including migration status as a control in the estimation of binominal logistic regressions for the probability of employment, informality, and overqualification. The data used corresponds to the pooled cross-section Continuous Household Surveys for 2012-2015. Results show a systematic disadvantage of foreignborn population in the access to job opportunities, as well as in a higher risk of overqualification and informality among those already employed. Females have lower chances of being employed, but we did not find a negative effect of the double disadvantage female-immigrant regarding the quality of employment. Despite the fact that the duration of residence inhibits the adverse effect of immigration on employment, ovequalification and informality, its impact does not vanish for oldest immigrants.
\end{abstract}

Keywords: immigration, return, educational mismatch, unemployment, informal employment.

\title{
Introducción
}

El análisis del censo de población de 2011 dio cuenta de algunos cambios en la composición por orígenes de la inmigración en Uruguay ${ }^{4}$, pero no captó el incremento ocurrido a partir de 2012. A diferencia de las encuestas continuas de hogares, los censos uruguayos no indagan en las variables que permiten identificar rasgos de precariedad en el empleo. El uso combinado de las Encuestas de Hogares del período 2012-2015 admite analizar ambos procesos: la profundización de las transformaciones de la migración ya identificadas en 2011, y la calidad de la inserción de los inmigrantes recientes en el mercado laboral uruguayo.

La mayoría de los estudios sobre migración reciente y trabajo se han concentrado en la población retornada ${ }^{5}$, y han sido escasos los trabajos que subrayan las dificultades de acceso de los inmigrantes recientes ${ }^{6}$. En cambio, en Argentina, Brasil o Chile, son múltiples los estudios que acumulan evidencia sobre las brechas que separan a la población autóctona de la inmigrante en indicadores de desempleo, inadecuación educativa, subempleo, salario y formalidad del empleo, y coinciden en señalar que estas distancias son aún mayores cuando se considera a los latinoamericanos de origen andino o caribeño ${ }^{7}$. El crecimiento

4 BENGOCHEA, Julieta. Inmigración reciente en Uruguay: 2005 - 2011; KOOLHAAS, Martín, NATHAN, Mathías. Inmigrantes internacionales y retornados en Uruguay: magnitud y características; PELLEGRINO, Adela. Migraciones.

5 KOOLHAAS, Martín. Migración internacional de retorno en Uruguay: magnitud, selectividad y reinserción laboral en tiempos de crisis económica internacional; PRIETO, Victoria. Las consecuencias de quedarse y de volver en el empleo de los uruguayos que migraron a España.

6 BENGOCHEA, op. cit.

7 SALA, Gabriela. Sobrecalificación de los migrantes del Cono Sur residentes en Argentina y Brasil; TORRES, Eduardo, CELTON, Dora. Discriminación salarial en Argentina entre nativos y paraguayos; MAGUID, Alicia, BRUNO, Sebastián. Migración, mercado de trabajo y movilidad 
reciente de la inmigración extrajera de estos últimos orígenes, y la evidencia de los países vecinos, en cuanto a una mayor prevalencia de precariedad laboral entre los inmigrantes intra-regionales, alientan a indagar cuáles son las características de la inserción laboral de los inmigrantes recientes en Uruguay.

Este país se ha posicionado a nivel legislativo como uno de los líderes del progresismo en materia de gestión migratoria, al aprobar las leyes № 18.250 y № $19.254^{8}$. Al mismo tiempo ha logrado sustantivas mejoras de los indicadores de su mercado laboral; en la última década se redujeron el subempleo, el desempleo y la informalidad, así como se recuperaron el salario y las instancias de negociación salarial ${ }^{9}$.

En este contexto amigable a la inmigración, interesa saber si las mejoras relativas a la inclusión de calidad en el mercado laboral uruguayo han estado al alcance de la población inmigrante. Concretamente, discutimos las características de la inserción laboral de los inmigrantes recientes en Uruguay y respondemos a esta pregunta mediante el análisis multivariado y la comparación sistemática de desempeños de inmigrantes extranjeros con nativos no migrantes y retornados.

El análisis multivariado pretende contrastar al menos tres hipótesis.

En primer lugar, se examina la hipótesis de un efecto negativo de la experiencia migratoria internacional sobre el acceso al empleo y la prevalencia de empleos de buena calidad (formalidad y adecuación ocupación-educación), mediante la inclusión del estatus migratorio de retornados e inmigrantes extranjeros en la estimación de las probabilidades de empleo, informalidad y sobrecalificación. También se estudia si existe un efecto específico del país de nacimiento y si éste perjudica o beneficia a determinados orígenes. La legislación uruguaya establece una distinción relevante al interior de la categoría de inmigrantes procedentes de países latinoamericanos no limítrofes, derivada por un lado de que se concede la residencia permanente a nacionales de países sudamericanos (Ley 19.254) y por otro establece el requisito del visado para nacionales de Cuba y República Dominicana. A priori puede pensarse que el primer grupo de orígenes se encuentra en ventaja frente a cubanos y dominicanos. Lamentablemente, dadas las características de la fuente de datos

ocupacional: el caso de los bolivianos y paraguayos en el Área Metropolitana de Buenos Aires; CERRUTTI, Marcela. Diagnóstico de las poblaciones de inmigrantes en la Argentina; STEFONI, Carolina, Mujeres inmigrantes peruanas en Chile.

8 La aprobación de la Ley № 18.250 concibe a los migrantes, extranjeros y retornados, como sujetos de derecho, iguales respecto a la población nativa no migrante. Más recientemente se aprobó también la Ley № 19.254 que asegura el acceso a la residencia permanente de los ciudadanos del MERCOSUR y Estados Asociados, y abarca a más de la mitad de los inmigrantes que recibe el país.

9 AMARANTE, Verónica, PERAZZO, Ivonne. Trabajo por cuenta propia y monotributo en Uruguay; ESPINO, Alma, MACHADO, Alina, ALVES, Guillermo. Estudio de las tendencias cuantitativas y cualitativas de la oferta laboral. 
utilizada, no es posible contrastar una hipótesis que establezca desempeños diferenciales al interior de este grupo, pero sí analizaremos si los orígenes latinoamericanos más numerosos (Brasil y Argentina) tienen un desempeño distinto del resto de regionales y de otros orígenes extra regionales (España, Estados Unidos, resto del mundo). En segundo lugar, se analiza si el tiempo de asentamiento reduce los riesgos de desempleo o de empleo precario entre los inmigrantes extranjeros, como ocurre entre los retornados ${ }^{10}$. Por último, se contrasta la hipótesis de un efecto diferencial del sexo por estatus migratorio, siguiendo la evidencia que arrojan trabajos anteriores en cuanto a que las retornadas tienen peores desempeños laborales que los varones con igual estatus migratorio ${ }^{11}$.

El artículo se estructura en cuatro secciones que siguen a esta introducción. La primera contextualiza el caso de estudio y revisa la literatura específica. La segunda sección se describe las fuentes y métodos empleados. La tercera sección presenta los principales resultados, y en la cuarta sección se incluyen las principales conclusiones.

\section{El mercado laboral uruguayo y la inmigración reciente}

El último informe SICREMI subraya el aumento en la migración intrarregional observada en América Latina entre los años 2010 y 2013 y la incorporación de nuevos orígenes al circuito migratorio cono sureño, entre los que destacan República Dominicana, Colombia y Venezuela ${ }^{12}$.

La inmigración intrarregional representa a la cuarta parte del total de la emigración de la región, y sus principales determinantes incluyen la creciente integración económica regional, la caída económica de los dos grandes destinos extra regionales de la emigración latinoamericana (Estados Unidos y Europa), y la confluencia del progresismo en la normativa migratoria latinoamericana ${ }^{13}$. A estos factores, se suman aquellos asociados a la dinámica del mercado de trabajo global. Ejemplo de lo anterior es la creciente demanda de trabajadoras del servicio doméstico, identificada como una de las razones de la feminización de la migración latinoamericana, y como una respuesta a la mercantilización e internacionalización del cuidado que genera la promoción socio-laboral

\footnotetext{
${ }_{10}$ KOOLHAAS, op. cit.

11 PRIETO, op. cit.

${ }^{12}$ Hasta ahora Venezuela había sido un destino principal en el concierto regional pero la ronda censal de 2010 indica un incremento de los venezolanos en los últimos diez años en varios países de la región. Uruguay como veremos no escapa de este circuito (MARTíNEZ-PIZARRO, Jorge, ORREGO-RIVERA, Cristian. Nuevas tendencias y dinámicas migratorias en América Latina y el Caribe).

${ }^{13}$ OECD, OEA. Tercer Informe del Sistema Continuo de Reportes sobre Migración Internacional en las Américas (SICREMI).
} 
de las mujeres ${ }^{14}$. En este marco se ha interpretado por ejemplo el flujo de latinoamericanas hacia España, Costa Rica ${ }^{15}$, Argentina ${ }^{16}$, Brasil ${ }^{17}$, y Uruguay ${ }^{18}$. Otro de los sectores de la economía global responsable de parte de la movilidad de personas de media y baja calificación son los servicios gastronómicos, hotelería y construcción. Cualquiera de estos sectores reúne ocupaciones con riesgo de precarización ${ }^{19}$.

En contextos de segmentación global del mercado de trabajo, las mayores dificultades tienen que ver con: la calidad del empleo y sus implicancias sobre la movilidad laboral ${ }^{20}$, el desajuste entre competencias y educación, y las formas de compatibilizar responsabilidades laborales y familiares de quienes tienen una red familiar transnacional. La complementariedad sociodemográfica entre nativos e inmigrantes ocurre en mercados laborales segmentados donde los inmigrantes ocupan el sector secundario -en términos del mercado de trabajo y no de sectores de actividad-, que conjuga bajos ingresos, informalidad y otras formas de precariedad ${ }^{21}$. Este esquema aplica a la interpretación de la inserción laboral de los inmigrantes latinoamericanos en la región, en España y en Estados Unidos 22 .

En Uruguay, aún persisten fracturas que segmentan al mercado laboral, volviendo aún más urgente el tipo de análisis que aquí desarrollamos. Desde el 2006, cayeron el desempleo, la informalidad y la desigualdad salarial, pero al mismo tiempo se ampliaron las brechas entre grupos de edad y sexo en el acceso a empleos de calidad ${ }^{23}$. Los sectores que crearon más empleo fueron

${ }_{14}$ VIDAL, Elena, VONO, Daniela. La inserción de las mujeres inmigradas en el mercado de trabajo español; HERRERA, Gioconda. Género y migración internacional en la experiencia latinoamericana. De la visibilización del campo a una presencia selectiva; HERRERA, Gioconda. Starting Over Again? Crisis, Gender, and Social Reproduction among Ecuadorian Migrants in Spain; VIDAL, Elena, GIL, Fernando, ANDREU, Domingo. La población femenina extracomunitaria en España. Análisis territorial de los factores de inserción laboral.

15 OECD, OEA, op. cit.

16 MAGUID, BRUNO, op. cit.

17 SALA, op. cit.

${ }^{18}$ GAINZA, Patricia. Hablando de derechos. Pensando en derechos humanos.

${ }^{19}$ BERNARDI, Fabricio, GARRIDO, Luis, MIYAR, María. The Recent Fast Upsurge of Immigrants in Spain and Their Employment Patterns and Occupational Attainment; HERRERA, Género y migración..., op. cit.; AYSA-LASTRA, María, CACHÓN, Lorenzo. Latino Immigrant Employment During the Great Recession: A Comparison of the United States and Spain.

${ }^{20}$ VIDAL-COSO, Elena, MIRET-GAMUNDI, Pau. The labour trajectories of immigrant women in Spain: Are there signs of upward social mobility?; BERNARDI, GARRIDO, MIYAR, op. cit.

${ }^{21}$ BERGER, Suzanne, PIORE, Michael. Dualism and Discontinuity in Industrial Society.

22 BERNARDI, GARRIDO, MIYAR, op. cit.; CERRUTTI, op. cit.; MAGUID, BRUNO, op. cit.; PORTES, Alejandro. Introduction: Immigration and Its Aftermath; GANDINI, Luciana, LOZANO, Fernando. The Effects of the Crisis on Occupational Segregation of Skilled Migrants from Latin America and the Caribbean in the United States, 2006-2012.

${ }^{23}$ AGEV. Reporte Social 2013. Principales características del Uruguay social; ESPINO, Alma, MACHADO, Alina, ALVES, Guillermo. Estudio de las tendencias cuantitativas y cualitativas de la oferta laboral. 
justamente la construcción y los servicios, ambos asociados a ocupaciones más vulnerables de media y baja calificación ${ }^{24}$.

Al mismo tiempo que se producían estas transformaciones en el mercado laboral uruguayo, también se modificaba la magnitud y la composición por orígenes de la inmigración que recibía este país ${ }^{25}$. Con posterioridad a la realización del censo de población de 2011, se ha corroborado una disminución de la población de origen brasileño y estadounidense así como un sostenido incremento de personas nacidas en España y en los países latinoamericanos no limítrofes. En adelante nos referiremos a estos últimos como los "nuevos orígenes latinoamericanos", incluyendo bajo esta categoría a los nacidos en Perú, Cuba, Colombia, México, Chile, Venezuela, Paraguay, Rep. Dominicana, Bolivia y Ecuador. Dentro de este heterogéneo grupo de nuevos orígenes latinoamericanos también se produjeron cambios de composición. Ha aumentado el peso de dominicanos, cubanos y venezolanos, en detrimento de peruanos, colombianos y paraguayos. Además, la composición por sexo de la recién llegada población extranjera se distancia parcialmente del equilibrio entre sexos de nativos y de otros orígenes más tradicionales. El análisis pormenorizado por país de nacimiento da cuenta de la coexistencia de orígenes feminizados, como Bolivia, Colombia, República Dominicana, Perú, Ecuador y Venezuela, con otros más equilibrados como Paraguay, o masculinizados como Cuba y México. Este rasgo de relativa feminización de los nuevos flujos no había sido percibido con tanta nitidez en el censo de población de $2011^{26}$. La comparación entre las encuestas de hogares del período 2012-2015 y el último censo insinúan que, con excepción de Venezuela, Paraguay, México y Ecuador, la prevalencia de mujeres en la inmigración reciente ha ido en aumento ${ }^{27}$.

Tanto los resultados del censo de población de $2011^{28}$, como de las encuestas de hogares combinadas para el período 2012-2015 indican que los inmigrantes recientes de cualquier origen alcanzan en mayor medida niveles superiores de instrucción ${ }^{29}$. Respecto a los argentinos y brasileños, los nacidos en el resto de Latinoamérica son más educados. La porción de inmigrantes con educación terciaria completa dentro de los nuevos orígenes latinoamericanos es dos veces y media mayor que la de las mujeres nativas no migrantes $(15,7 \%)$ y cinco veces más que la de varones nativos (9,5\%). Finalmente, el otro rasgo distintivo de los nuevos orígenes latinoamericanos se encuentra en la

\footnotetext{
${ }^{24}$ AGEV, op. cit., p. 65.

${ }^{25}$ PP-MIDES. Integración de la población extranjera y retornada en Uruguay.

${ }^{26}$ BENGOCHEA, op. cit.

27 PP-MIDES, op. cit.

${ }^{28}$ BENGOCHEA, op. cit.; KOOLHAAS, op. cit.

${ }^{29}$ PP-MIDES, op. cit.
} 
composición por nivel educativo de la población de varones y mujeres. Para el resto de orígenes (salvo para la categoría residual de orígenes) y para los nativos no migrantes, la prevalencia de población más educada es mayor entre las mujeres. En cambio, en este grupo el $44 \%$ de las mujeres y el $48 \%$ de los varones tienen estudios superiores.

\section{Datos y métodos}

El siguiente análisis se basa en la explotación de las Encuestas Continuas de Hogares (ECH) del período 2012-2015, la fuente con información más completa sobre la calidad del empleo. La ECH es relevada por el Instituto Nacional de Estadística (INE) en los hogares particulares uruguayos desde 1981. Desde 2006 la muestra es representativa de toda la población del país residente en hogares particulares (incluyendo las pequeñas localidades urbanas y las áreas rurales). En la actualidad constituye la principal fuente continua de información sobre inmigración internacional, pues incorpora un módulo de migración idéntico al del censo de población 2011. Desde 2007 aproximadamente un 4\% de los hogares uruguayos son encuestados anualmente por la ECH (aproximadamente 144.000 personas y 50.000 hogares).

Aunque su tamaño muestral desafía la formulación de inferencias significativas al trabajar con poblaciones que representan menos del 0,5\% en la población uruguaya, como en este caso, es posible sortear esta limitación al combinar varias muestras anuales. Aquí se analizan las muestras 2012-2015, consiguiendo un incremento sustantivo del número de inmigrantes recientes entrevistados (2.119 casos) y de inmigrantes recientes de origen latinoamericano $(1.129)^{30}$. De todos modos, para evitar inferencias inapropiadas, no se realiza un análisis a nivel de países de origen, distinguiendo solo a nivel de país para los orígenes más numerosos (Argentina, Brasil, España y Estados Unidos).

Se estimaron tasas de actividad, empleo y desempleo, y la proporción de trabajadores ocupados sin cobertura de seguridad social. Se entiende por informalidad a la ausencia de protección social, medida como la carencia absoluta de aportes a cajas de jubilaciones en el país (BPS, AFAP, Policial, Militar, Profesional, Notarial, Bancaria). Se asume aquí que una persona ocupada en situación de formalidad plena realiza aportes independientemente de si el aporte se hace por la totalidad del salario o por una parte de éste.

\footnotetext{
30 Si bien los resultados de la estrategia de fusión de los ficheros 2012 a 2015 ha sido exitosa, es preciso explicitar algunas modificaciones del plan muestral que tienen lugar en este período en que ocurren dos cambios significativos en este sentido. En primer lugar, a partir del 2012 en forma parcial y completamente a partir del 2013, se cambia el marco muestral como resultado de la realización del censo de población en el año 2011. Consecuentemente, se actualizan las proyecciones de población para años sucesivos y se alteran los expansores poblacionales. En segundo lugar, en la encuesta del año 2015 se complejiza el diseño de la muestra con etapas de estratificación adicionales.
} 
Para evaluar la adecuación entre la cualificación adquirida y la cualificación esperada de las ocupaciones se recurrió a la clasificación propuesta por la Organización Internacional del Trabajo ${ }^{31}$ que se describe en detalle en la siguiente tabla.

\section{Tabla 1 - Grandes grupos de ocupación y nivel educativo que demanda su desempeño}

\begin{tabular}{|c|c|c|}
\hline CIUO 08 (1 dígito) & $\begin{array}{l}\text { Grandes grupos de } \\
\text { ocupación }\end{array}$ & $\begin{array}{l}\text { Nivel educativo } \\
\text { esperado }\end{array}$ \\
\hline 1 - Directores y gerentes & \multirow{3}{*}{$\begin{array}{l}\text { Alta calificación no } \\
\text { manual }\end{array}$} & \multirow{3}{*}{ Terciaria completa } \\
\hline 2 - Profesionales científicos e intelectuales & & \\
\hline 3 - Técnicos y profesionales de nivel medio & & \\
\hline 4 - Personal de apoyo administrativo & \multirow[b]{2}{*}{$\begin{array}{l}\text { Baja calificación no } \\
\text { manual }\end{array}$} & \multirow{5}{*}{$\begin{array}{l}\text { Secundaria } \\
\text { completa }\end{array}$} \\
\hline $\begin{array}{l}5 \text { - Trabajadores de los servicios y vendedores de } \\
\text { comercios y mercados }\end{array}$ & & \\
\hline $\begin{array}{l}6 \text { - Agricultores y trabajadores calificados } \\
\text { agropecuarios, forestales y pesqueros }\end{array}$ & \multirow{3}{*}{ Manual calificado } & \\
\hline $\begin{array}{l}7 \text { - Oficiales, operarios y artesanos de artes } \\
\text { mecánicas y de otros oficios }\end{array}$ & & \\
\hline $\begin{array}{l}8 \text { - Operadores de instalaciones y máquinas y } \\
\text { ensambladores }\end{array}$ & & \\
\hline 9 - Ocupaciones elementales & No calificado & $\begin{array}{c}\text { Primaria completa } \\
\text { o menos }\end{array}$ \\
\hline
\end{tabular}

Fuente: tomado de las clasificaciones utilizadas por la Organización Internacional del Trabajo ${ }^{32}$.

De acuerdo a este esquema se construyó una variable que clasifica a la población ocupada en: i) subcalificada, que se desempeña en tareas que demandan un grado de calificación mayor al alcanzado; ii) sobrecalificada, que se desempeña en tareas que demandan un grado de calificación menor al alcanzado; y iii) inserción adecuada, la proporción de los que no sufren problemas de desajuste educativo, es decir que se desempeñan en tareas acordes a su formación.

Por último se estimaron tres grupos de modelos logísticos binomiales para predecir las probabilidades de: i) empleo de la población en edad de trabajar (PET), ii) informalidad en el empleo de los ocupados, y iii) sobrecalificación en la ocupación principal de los trabajadores. En los tres casos se incluye al estatus migratorio para contrastar la hipótesis de que con independencia del sexo, la edad, y el año de observación, el estatus de inmigrante reciente o retornado reciente introduce un mayor riesgo de desempleo o precariedad laboral. El

\footnotetext{
31 SPARREBOOM, Theo, STANEVA, Anita. Is education the solution to decent work for youth in developing economies?

32 Ibidem.
} 
nivel educativo se incluye como control en los modelos que predicen empleo e informalidad pero se excluye en el de sobrecalificación por ser colineal con la independiente. En los modelos que estiman probabilidad de empleo informal y de sobrecalificación en la ocupación principal incorporan categoría de ocupación (asalariado, cuenta propia sin local, cuenta propia con local, patrón o cooperativista), y calificación de la ocupación (ninguna, manual, no manual de baja calificación, y no manual de alta calificación).

Por último, para analizar la existencia de un efecto diferencial del estatus migratorio según sexo se incorporaron términos de interacción. De esta forma se contrastó la hipótesis de que la vulnerabilidad de la población femenina en el mercado laboral opere de forma diferencial según estatus migratorio y país de nacimiento.

\section{Resultados}

En Uruguay el mercado de trabajo es el eje vertebrador de los procesos de integración de los migrantes laborales y de sus familiares, pues la inserción laboral es la puerta de entrada al ejercicio de derechos de salud, educación y para los derechos derivados de gran parte de la política social. En esta sección se analizan los indicadores elementales de acceso al empleo de los activos y se evalúa la prevalencia de informalidad y la adecuación entre instrucción y el tipo de tareas de la ocupación principal. En una primera parte se presenta el análisis bivariado y seguidamente se comentan los resultados de modelos multivariados estimados para la probabilidad de empleo, informalidad y sobrecalificación.

\section{La incidencia del desempleo, la informalidad y la sobrecalificación según estatus migratorio. Análisis bivariado}

Varones y mujeres inmigrantes, extranjeros o retornados, registran niveles de desempleo muy superiores a los de la población no migrante y a los extranjeros que llevan más tiempo en el país. El desempleo de este último grupo es incluso inferior al de los no migrantes, lo que sugiere que a mayor tiempo de residencia es esperable una mayor inserción en el mercado de trabajo. Este rasgo ha sido señalado en la explotación del censo de $2011^{33}$, pero aquí se verifica su vigencia para los años más recientes. Además, la brecha entre sexos -que afecta a las mujeres-, es más pronunciada entre los extranjeros recién llegados (gráfico 1).

\footnotetext{
${ }^{33}$ BENGOCHEA, op. cit.; KOOLHAAS, Martín, NATHAN, Mathías. Inmigrantes internacionales y retornados en Uruguay: magnitud y características.
} 


\section{Gráfico 1 - Tasa de desempleo por nivel educativo, estatus migratorio y sexo, 2012-2015}

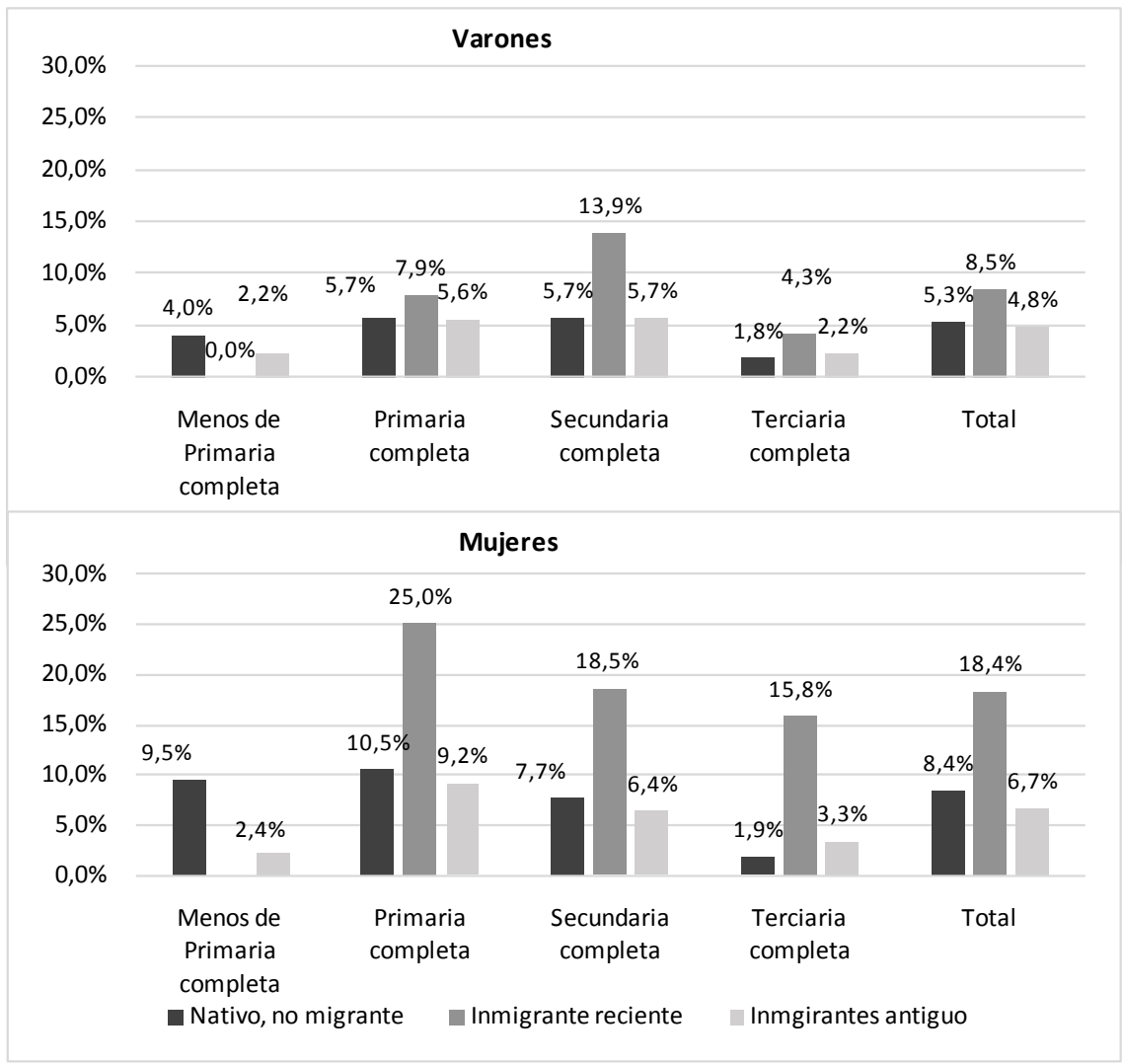

Fuente: elaborado a partir de las Encuestas Continúas de Hogares 2012-2015, INE.

Nota: las estimaciones para los inmigrantes recientes que no alcanzaron a completar Educación Primaria fueron excluidas por no ser significativas.

Si se incorpora el nivel educativo alcanzado en la descripción de las tasas de desempleo de la población por condición migratoria, se encuentra que la desventaja de los inmigrantes recientes en el acceso al empleo se mantiene a lo largo de todo el espectro de capital humano (Gráfico 1). Además el efecto protector de la educación frente al desempleo no se verifica para los inmigrantes recientes varones y es muy débil para las mujeres más educadas de este grupo. Los extranjeros varones recién llegados que completaron la secundaria tiene la mayor tasa de desempleo (13,9\%), y entre las mujeres es llamativa la distancia que separa a las nativas no migrantes que completaron la educación terciaria $(1,9 \%)$ de sus pares extranjeras recién llegadas $(15,8 \%)$. 
Analicemos ahora las características de la ocupación para quienes tienen empleo. En el Gráfico 2 se presenta la distribución de la población con empleo por nivel de calificación de la ocupación principal. Es posible notar que la población extranjera recién llegada nacida en países latinoamericanos no limítrofes tiende a concentrarse en ocupaciones de baja calificación (38\%) y alta calificación (32,8\%).

\section{Gráfico 2 - Distribución relativa de la población ocupada por calificación de la ocupación principal según condición migratoria. Uruguay, 2012-2014}

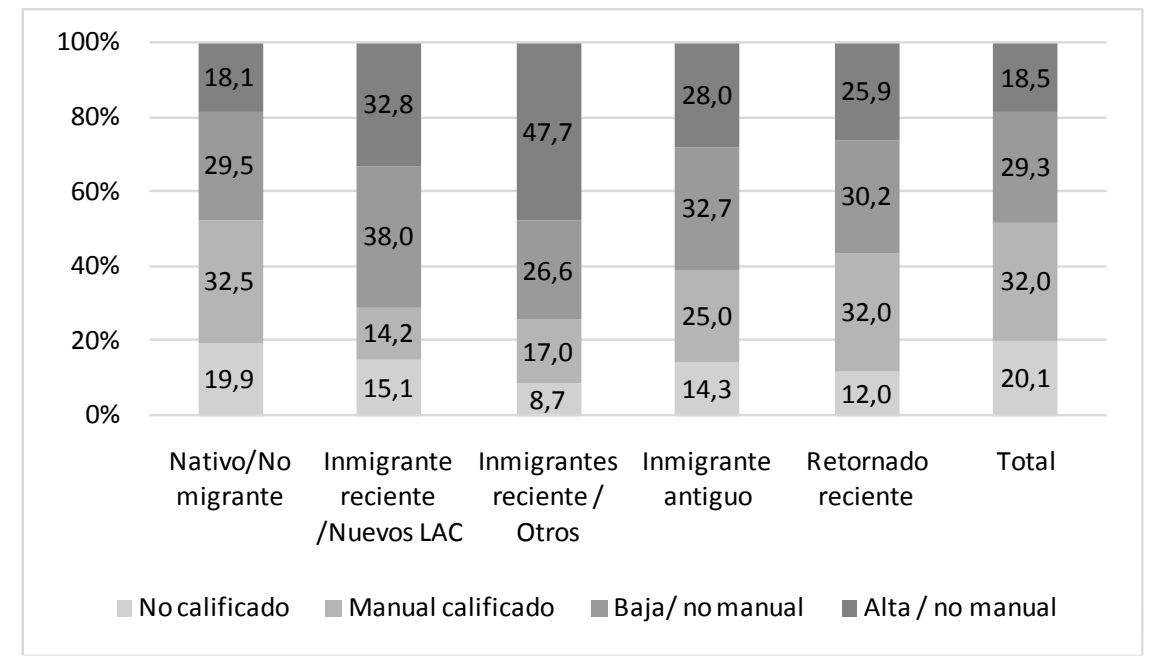

Fuente: elaborado a partir de las Encuestas Continúas de Hogares 2012-2014, INE.

En el espectro de calificación la inserción de los inmigrantes de los nuevos orígenes latinoamericanos dista de la del conjunto de la población residente así como del resto de inmigrantes extranjeros y retornados (gráfico 2). Mientras que retornados y nativos no migrantes tienen una similar distribución relativa de ocupaciones según calificación, los inmigrantes recientes están sobrerepresentados en ocupaciones de calificación media y alta, siendo especialmente fuerte la concentración de trabajadores muy calificados entre los inmigrantes recientes extra regionales. Los inmigrantes procedentes de los nuevos orígenes latinoamericanos se concentran en ocupaciones de calificación media (manual calificada, 38\%) y alta (Alta/No manual, 32,8\%), donde la participación de la población nativa no migrante es menor (apenas 5 de cada 10 ocupados). Ello indicaría cierta complementariedad en la inserción laboral de inmigrantes recientes de este origen $(70,8 \%)$, del resto de orígenes extranjeros $(74,3 \%)$, y la inserción de la población nativa $(47,6 \%)$.

También entre los ocupados la incidencia de la informalidad, es decir la proporción de personas que no realizan aportes a la Caja de Jubilaciones, por 
lo que no contribuyen al sistema de Seguridad Social, difiere de la encontrada para los nativos no migrantes, aunque en este caso las diferencias entre nativos y extranjeros son mínimas (gráfico 3). Un 25,4\% de los trabajadores uruguayos no realiza aportes a la seguridad social y esta proporción es apenas inferior $(23,9 \%)$ en el conjunto de los inmigrantes recientes y algo superior entre los inmigrantes que llevan más de 5 años en el país $(27,1 \%)$. Las diferencias en la prevalencia de informalidad por estatus migratorio son mínimas, pero las diferencias entre sexos indican una ventaja de las mujeres en una menor prevalencia de informalidad que se mantiene en todos los estatus migratorios con excepción de los inmigrantes más antiguos.

\section{Gráfico 3 - Prevalencia de informalidad entre la población ocupada según sexo y condición migratoria, 2012-2015}

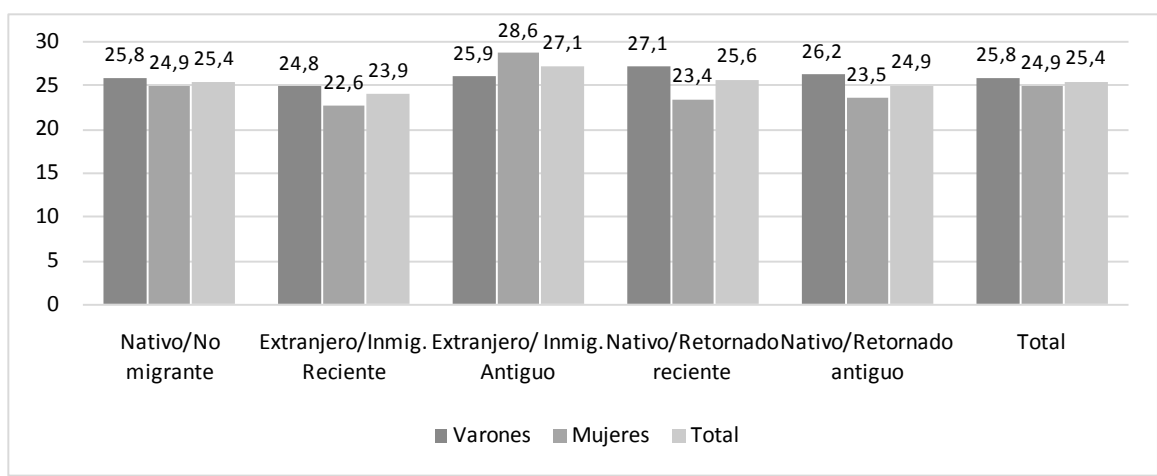

Fuente: elaborado a partir de las Encuestas Continúas de Hogares 2012-2015, INE.

Nota: no se distingue entre inmigrantes recientes por origen debido al reducido número de casos de este grupo que se encuentran en situación de informalidad.

La Encuesta Continua de Hogares también permite analizar la incidencia de la inadecuación entre educación alcanzada y competencias requeridas por la ocupación desempeñada, según condición migratoria. Los resultados indican que la incidencia de sobrecalificación es el principal problema de inadecuación entre los inmigrantes recientes, entre quienes alcanza 18\% entre varones y $26 \%$ entre las mujeres (gráfico 4). Respecto a la población nativa, ello supone una prevalencia tres veces superior entre los varones y cuatro veces entre las mujeres. Sin embargo, entre quienes llevan más de cinco años en el país se observa un significativo descenso de la incidencia de este problema de desajuste entre escolaridad alcanzada y calificación demandada. En este caso las diferencias entre retornados e inmigrantes se mantienen independientemente del tiempo de asentamiento lo que hace pensar en un diferencial no asociable a la migración sino a otros rasgos propios de los inmigrantes -recuérdese que en promedio estos últimos son mucho más educados que los nativos no migrantes y retornados-. 


\section{Gráfico 4 - Desajuste educativo de la población ocupada de 25-64 años por sexo y condición migratoria, 2012-2014}

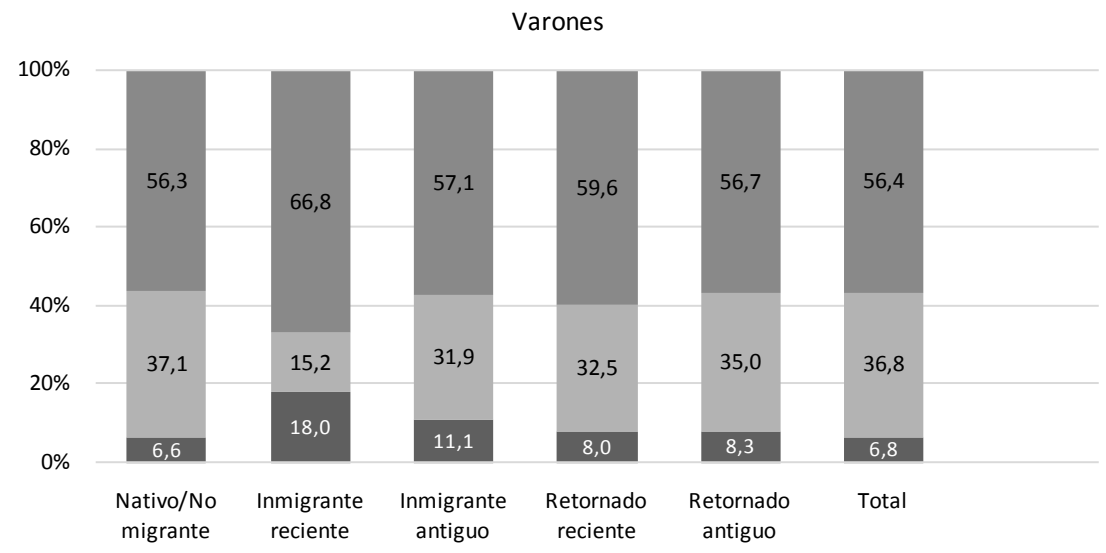

Mujeres

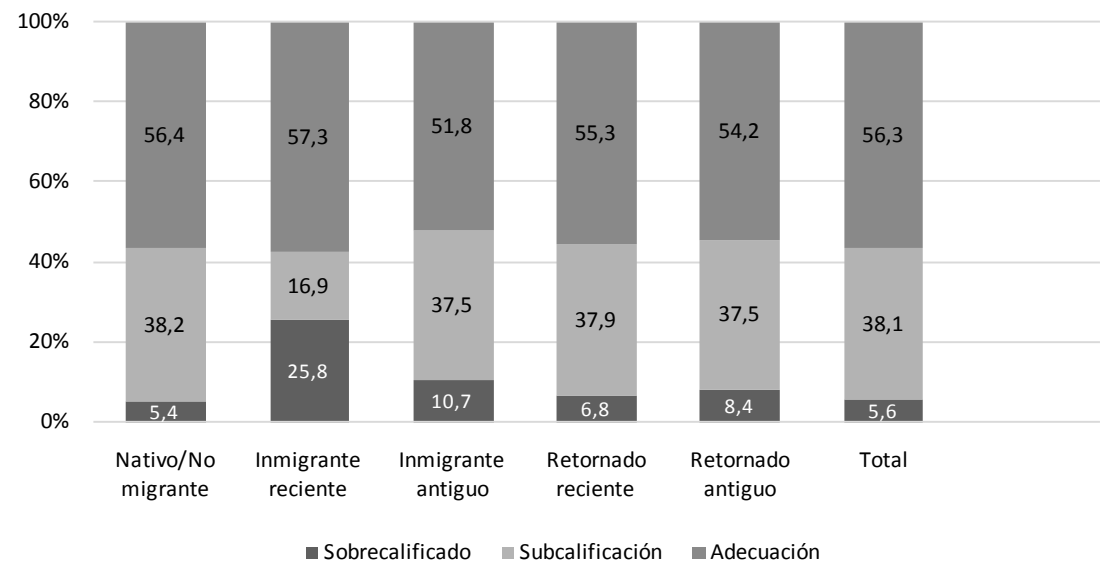

Fuente: elaborado a partir de las Encuestas Continúas de Hogares 2012-2014, INE.

En las siguientes tablas se presentan los resultados de los modelos logísticos binomiales ajustados para predecir tres fenómenos diferentes. Un primer grupo de modelos predice la probabilidad de tener un empleo para las personas en edad de trabajar, incluyendo a activos e inactivos (tabla 2). El segundo grupo de modelos, analiza la probabilidad de los ocupados de estar empleados de manera informal, es decir de no realizar aportes a la seguridad social (tabla 3). Finalmente, se estima la probabilidad de desempeñarse en una ocupación para la que se está sobrecalificado (tabla 4). 


\section{El sexo, la edad y la educación como predictores de la inserción laboral en el análisis multivariado}

Las mujeres tienen menor probabilidad de acceso al empleo (70\% menos) y mayor riesgo de estar ocupadas en empleos informales (46\% más) (tabla 2 y 3 ). Sin embargo, cuando se analiza la prevalencia de sobrecalificación, las mujeres tienen aproximadamente dos puntos porcentuales menos de riesgo de estar sobrecalificadas en el tipo de tarea que desempeñan respecto a los varones (tabla 4). La edad tiene un efecto positivo -aunque no lineal- sobre el acceso al empleo (tabla 2) y sobre la probabilidad de sobrecalificación (tabla 4), es decir que a mayor edad, mayor calificación adquirida y, por ende, mayor riesgo de no encontrar las recompensas acordes a la formación acumulada. En cambio, la edad guarda una relación inversa con la probabilidad de empleo informal entre los ocupados, quienes tienen más probabilidades de estar inscriptos en el sistema de seguridad social en los primeros años de su vida laboral. El efecto no lineal de la edad refleja lo que señalábamos en los antecedentes: en Uruguay la entrada al mercado de trabajo es especialmente problemática para los segmentos más jóvenes y para los de edad más avanzada.

Por último, la educación tiene el comportamiento esperado de protección frente al desempleo (tabla 2) y la informalidad (tabla 3), aumentando la probabilidad de estar empleado y reduciendo la de encontrarse en empleos informales a medida que se incrementa la escolarización alcanzada.

\section{La condición migratoria en el acceso al empleo y sus interacciones con el sexo en el análisis multivariado}

Analicemos ahora la primera de la hipótesis que discute este trabajo, la existencia de un efecto negativo de la condición de inmigrante reciente sobre el acceso al empleo de calidad. Al controlar por el sexo, la edad, el año de la encuesta y el nivel educativo, la condición de retornado o extranjero llegado al país en los últimos cinco años reduce a la mitad la probabilidad de empleo respecto a los nativos no migrantes (modelo 1 en tabla 2). Tal efecto sobre el acceso al trabajo no desaparece entre los inmigrantes extranjeros que llevan más tiempo de asentamiento -aunque reduce su severidad-, como sí ocurre entre los retornados al cabo de seis años. Si excluimos del análisis a los retornados y nos centramos en el efecto del país de nacimiento sobre el acceso al empleo (modelo 2 en tabla 2), se comprueba que existe un efecto significativo y positivo de los nacidos en países limítrofes de Uruguay, y que no se encuentra efecto alguno para los que hemos denominado nuevos orígenes Latinoamericanos. Los migrantes de Argentina y Brasil, duplican en oportunidades de empleo a los nativos no migrantes y al resto de orígenes extranjeros, pero no habría una desventaja específica en el empleo para el resto de orígenes inmigrantes. 


\section{Tabla 2 - Resultados de modelo logístico binomial para la probabilidad de estar ocupado. Uruguay, 2012-2015}

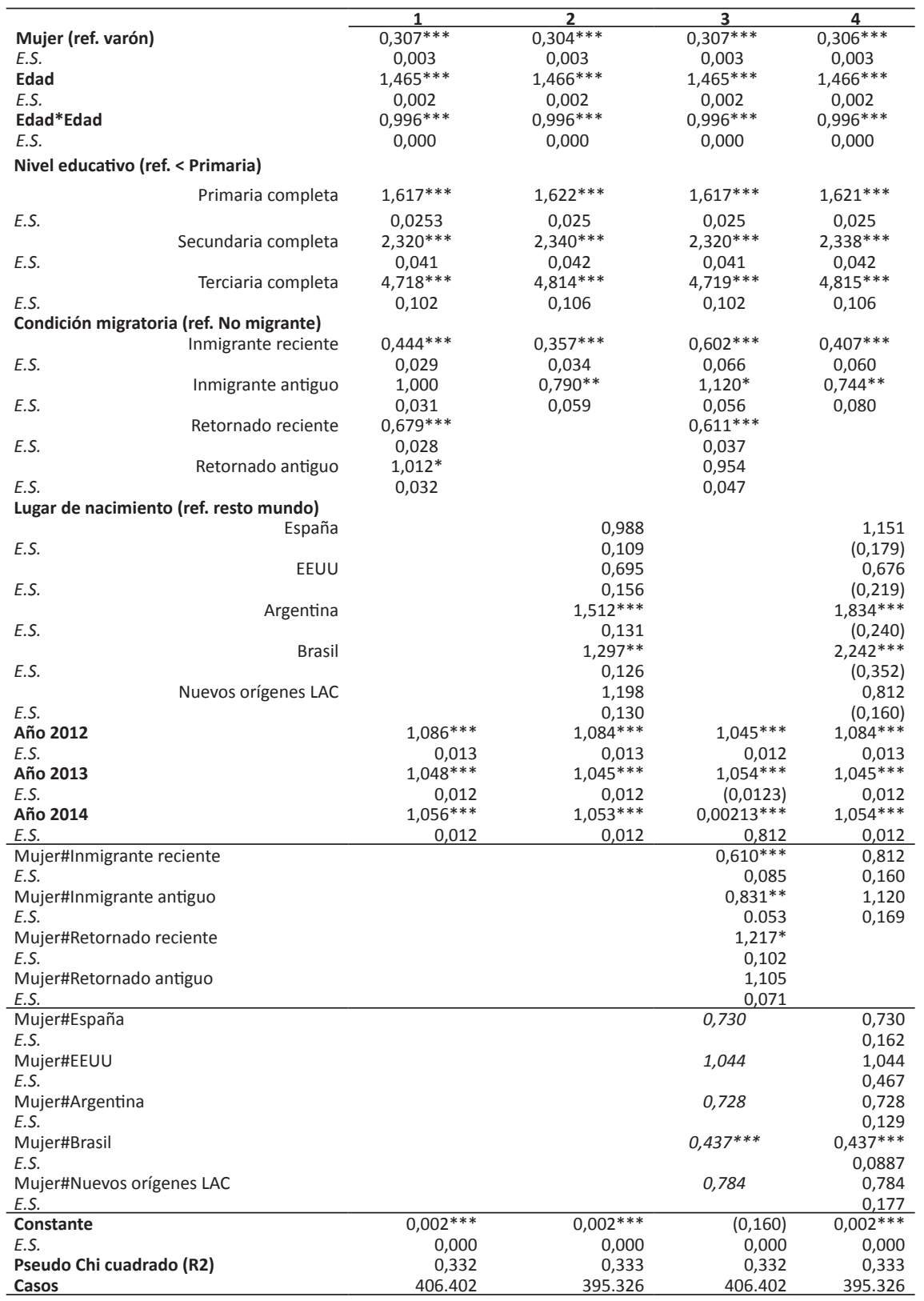

Nota: ${ }^{*} \mathrm{p}<0.05,{ }^{* *} 0.01,{ }^{* * *} 0.001$, E.S. error estándar. Los modelos 2 y 4 excluyen a la población retornada. Este grupo de modelos incluye a todas las personas en edad de trabajar. 
La segunda de las hipótesis que buscamos contrastar alude a la existencia de un efecto diferencial del sexo por estatus migratorio. En el tercero de los modelos del grupo que estima la probabilidad de acceder al empleo, se incluyen interacciones del sexo y el estatus migratorio (modelo 3 en tabla 2). En este caso la doble condición de mujer e inmigrante reciente o antigua comprometen aún más la inserción laboral -de por sí difícil- de las mujeres. Sin embargo, en sintonía con trabajos anteriores ${ }^{34}$, esta doble desventaja de mujer e inmigrante no se corrobora entre las mujeres retornadas; por el contrario, éstas tienen una probabilidad de acceso al empleo incluso superior a la de los varones nativos no migrantes. En el cuarto de los modelos estimados para predecir las probabilidades de acceso al empleo (tabla 2), se analiza específicamente el efecto de ser mujer y pertenecer a un determinado país, y en este caso el efecto negativo de ser mujer e inmigrante parece ser independiente del país de procedencia excepto para las mujeres brasileñas, entre quienes se reducen aún más las oportunidades de empleo respecto a los varones brasileños y nativos no migrantes.

\section{La condición migratoria y la informalidad. Un análisis multivariado}

El segundo grupo de modelos ajustados estima la probabilidad de los ocupados de tener un empleo informal, es decir de no aportar al sistema de Seguridad Social (tabla 3). En esta estimación, además de los controles de edad, sexo, educación, estatus migratorio y lugar de nacimiento, se tuvieron en cuenta las características de las ocupaciones. Concretamente se integró la categoría ocupacional (trabajador asalariado, cuentapropista con local, cuentrapropista sin local, y patrón o cooperativista,) y el nivel de calificación (alta y no manual, baja y no manual, manual o ninguna). Los resultados indican que el riesgo de informalidad se asocia positivamente con la condición de trabajo no asalariado. Como era de esperar en función de la heterogeneidad de este grupo, dicha probabilidad es mucho más elevada en la categoría de cuentapropistas sin local ni inversión, pero de todos modos no es despreciable el riesgo de quienes trabajan por cuenta propia con local, ni el de patrones y cooperativistas ${ }^{35}$. Con respecto a la estratificación de las ocupaciones por calificación, corroboramos la existencia de una relación negativa entre el nivel de calificación y la probabilidad de ser contratado en condiciones de informalidad. Como es lógico, las personas que se desempeñan en ocupaciones de mayor jerarquía en la estructura ocupacional son menos propensas a la informalidad laboral que aquellos ocupados en puestos que no demandan calificación alguna.

Similar a lo encontrado en relación al acceso al empleo, en la estimación de probabilidad de informalidad se aprecia una desventaja específica de

\footnotetext{
34 KOOLHAAS, op. cit.

${ }^{35}$ Recuérdese que dentro del grupo de asalariados se incluye a los trabajadores del sector privado y público. Para este segundo grupo la prevalencia de formalidad en el empleo es de $99 \%$.
} 
los inmigrantes recientes: tanto extranjeros como retornados tienen mayor riesgo de tener un empleo informal, aunque este efecto se reduzca entre quienes llevan más de cinco años en Uruguay. Al incluir el control del país de nacimiento se encuentra que el riesgo de informalidad afecta 7 y más de 2,5 veces más a los estadounidenses y brasileños que a los nativos (modelo 2, tabla $3)$, respectivamente. Nótese que éstos son dos orígenes que deben superar una barrera lingüística. Entre los españoles el riesgo es inferior al de los nativos y los inmigrantes de los nuevos orígenes de inmigración latinoamericanos tienen $79 \%$ más probabilidades de tener un empleo informal respecto al resto de orígenes (modelo 4 en tabla 3).

En este caso, las interacciones entre sexo y estatus migratorio arrojan un resultado distinto del encontrado en el análisis del acceso al empleo. Si bien las mujeres tienen un $45 \%$ más de probabilidades de trabajar sin cotizar a la Seguridad Social, éste riesgo se reduce cuando se incluyen las interacciones con la condición migratoria. De hecho, haber nacido en alguno de los países de los nuevos orígenes latinoamericanos reduce en un $75 \%$ el riesgo de informalidad en el empleo femenino (modelo 4 en tabla 4).

Tabla 3 - Resultados de modelo logístico binomial para la probabilidad de estar ocupado sin realizar aportes a la Seguridad Social (informalidad). Uruguay, 2012-2014

\begin{tabular}{|c|c|c|c|c|}
\hline & 1 & 2 & 3 & 4 \\
\hline Mujer (ref. varón) & $1.465^{* * *}$ & $1.469 * * *$ & $1.468^{* * *}$ & $1.467^{* * *}$ \\
\hline E.S. & 0.034 & 0.035 & 0.035 & 0.035 \\
\hline Edad & $0.813 * * *$ & $0.812 * * *$ & $0.813^{* * *}$ & $0.812^{* * *}$ \\
\hline E.S. & 0.003 & 0.003 & 0.003 & 0.003 \\
\hline Edad*Edad & $1.002 * * *$ & $1.002 * * *$ & $1.002 * * *$ & $1.002 * * *$ \\
\hline E.S. & 0.000 & 0.000 & 0.000 & 0.000 \\
\hline \multicolumn{5}{|l|}{ Nivel educativo (ref. < Primaria) } \\
\hline Primaria completa & $0.374 * * *$ & $0.375^{* * *}$ & $0.373 * * *$ & $0.375 * * *$ \\
\hline E.S. & 0.014 & 0.014 & 0.014 & 0.014 \\
\hline Secundaria completa & $0.129 * * *$ & $0.128 * * *$ & $0.129 * * *$ & $0.128 * * *$ \\
\hline 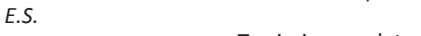 & 0.006 & 0.006 & 0.006 & 0.006 \\
\hline Terciaria completa & $0.039 * * *$ & $0.039 * * *$ & $0.039 * * *$ & $0.039 * * *$ \\
\hline & 0.003 & 0.003 & 0.003 & 0.003 \\
\hline \multicolumn{5}{|l|}{ Condición migratoria (ref. No migrante) } \\
\hline Inmigrante reciente & $3.684 * * *$ & $3.274 * * *$ & $4.063^{* * *}$ & $2.891 * *$ \\
\hline E.S. & 0.579 & 0.882 & 0.790 & 0.952 \\
\hline Inmigrante antiguo & $1.275^{*}$ & 1.063 & $1.214^{*}$ & 0.887 \\
\hline 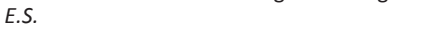 & 0.093 & 0.242 & 0.110 & 0.244 \\
\hline Retornado reciente & $1.622 * * *$ & & $1.712 * * *$ & \\
\hline ( & 0.146 & & 0.182 & \\
\hline Retornado antiguo & $1.215^{* *}$ & & $1.249 * *$ & \\
\hline 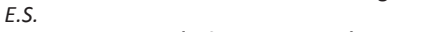 & 0.086 & & 0.106 & \\
\hline Lugar nacimiento (ref. resto mundo) & & & & \\
\hline España & & $0.275^{* * *}$ & & $0.208^{* * *}$ \\
\hline E.S. & & 0.097 & & 0.091 \\
\hline Estados Unidos & & $7.840 * * *$ & & $13.11 * * *$ \\
\hline E.S. & & 4.489 & & 8.775 \\
\hline Argentina & & 1.291 & & 1.631 \\
\hline E.S. & & 0.3 & & 0.455 \\
\hline Brasil & & $2.566 * * *$ & & $3.182 * * *$ \\
\hline E.S. & & 0.639 & & 0.942 \\
\hline Nuevos orígenes LAC & & 1.118 & & $1.973^{*}$ \\
\hline E.S. & & 0.323 & & 0.682 \\
\hline
\end{tabular}




\begin{tabular}{|c|c|c|c|c|}
\hline \multirow[t]{2}{*}{ Independiente sin local } & $193.6 * * *$ & $196.6 * * *$ & $193.7 * * *$ & $196.7 * * *$ \\
\hline & 23.9 & 24.77 & 23.9 & 24.79 \\
\hline \multirow{2}{*}{ Independiente con local } & $22.7^{* * *}$ & $22.86 * * *$ & $22.7^{* * *}$ & $22.76 * * *$ \\
\hline & 0.544 & 0.555 & 0.544 & 0.555 \\
\hline \multirow{2}{*}{$\begin{array}{l}\text { E.S. } \\
\text { Patrón/cooperativista } \\
\text { E.S. }\end{array}$} & $1.750 * * *$ & $1.731 * * *$ & $1.751 * * *$ & $1.734 * * *$ \\
\hline & 0.084 & 0.085 & 0.084 & 0.085 \\
\hline \multicolumn{5}{|l|}{ Cualificación (ref. ninguna) } \\
\hline Manual & $0.590 * * *$ & $0.593 * * *$ & $0.590 * * *$ & $0.593 * * *$ \\
\hline E.S. & 0.015 & 0.016 & 0.015 & 0.016 \\
\hline \multirow[t]{2}{*}{ Baja cualificación /No manual } & $0.481 * * *$ & $0.485^{* * *}$ & $0.481 * * *$ & $0.485^{* * *}$ \\
\hline & 0.013 & 0.013 & 0.013 & 0.013 \\
\hline \multirow[t]{2}{*}{ Alta cualificación /No manual } & $0.287 * * *$ & $0.283^{* * *}$ & $0.287^{* * *}$ & $0.282 * * *$ \\
\hline & 0.012 & 0.012 & 0.012 & 0.012 \\
\hline Año 2012 & $0.863 * * *$ & $0.859 * * *$ & $0.863^{* * *}$ & $0.860 * * *$ \\
\hline E.S. & 0.021 & 0.021 & 0.021 & 0.021 \\
\hline Año 2013 & $0.880^{* *}$ & $0.879 * * *$ & $0.880 * * *$ & $0.879 * * *$ \\
\hline E.S. & 0.021 & 0.021 & 0.021 & 0.021 \\
\hline \multicolumn{2}{|l|}{ Mujer*Inmigrante reciente } & & 0.760 & 1.618 \\
\hline \multicolumn{2}{|l|}{ E.S. } & & 0.250 & 0.919 \\
\hline \multicolumn{2}{|l|}{ Mujer*Inmigrante antiguo } & & 1.153 & 1.771 \\
\hline \multicolumn{2}{|l|}{ E.S. } & & 0.177 & 0.858 \\
\hline \multicolumn{2}{|l|}{ Mujer*Retornado reciente } & & 0.829 & \\
\hline \multicolumn{2}{|l|}{ E.S. } & & 0.167 & \\
\hline \multicolumn{2}{|l|}{ Mujer*Retornado antiguo } & & 0.915 & \\
\hline \multicolumn{2}{|l|}{ E.S. } & & 0.140 & \\
\hline \multicolumn{2}{|l|}{ Mujer*España } & & & 2.405 \\
\hline \multicolumn{2}{|l|}{ E.S. } & & & 1.886 \\
\hline \multicolumn{2}{|l|}{ Mujer*Estados Unidos } & & & 0.181 \\
\hline & & & 0.244 \\
\hline \multicolumn{2}{|l|}{ Mujer*Argentina } & & & 0.654 \\
\hline \multicolumn{2}{|l|}{ E.S. } & & & 0.338 \\
\hline \multicolumn{2}{|l|}{ Mujer*Brasil } & & & 0.644 \\
\hline \multicolumn{2}{|l|}{ E.S. } & & & 0.362 \\
\hline Mujer*Nuevos orígenes LAC & & & & $0.252^{* *}$ \\
\hline E.S. & & & & 0.162 \\
\hline Constante & $47.48 * * *$ & $49.10 * * *$ & $47.52 * * *$ & $49.34 * * *$ \\
\hline E.S. & 3.779 & 3.952 & 3.783 & 3.973 \\
\hline Chi cuadrado (R2) & 0.346 & 0.346 & 0.346 & 0.346 \\
\hline Casos & 104,677 & 101,682 & 104,677 & 101,682 \\
\hline
\end{tabular}

Nota: $* \mathrm{p}<0.05, * * 0.01, * * * 0.001$, E.S. error estándar. Los modelos 2 y 4 excluyen a la población retornada.

Este grupo de modelos incluye únicamente a las personas ocupadas.

\section{La condición migratoria y sobrecalificación en el empleo. Un análisis multivariado}

El tercer y último grupo de modelos predice la probabilidad de sobrecalificación. En este caso se excluyen los casos de subcalificación que también representan un problema de inadecuación educativa pero es menos común entre los inmigrantes extranjeros y menos problemático para la movilidad laboral y su integración social.

En este caso los trabajadores más vulnerables son los varones, quienes se desempeñan en tareas no manuales pero de baja cualificación, los patrones o miembros de cooperativa y los inmigrantes extranjeros.

Los resultados indican que éste es uno de los problemas de empleo al que se encuentra más expuesto este último grupo poblacional. Si se compara el tamaño de las razones de momios de las tablas 3 y 4 se encuentra que el estatus de inmigrante reciente incrementa el riesgo de informalidad y sobrecalificación, pero que la magnitud de este efecto es sustantivamente mayor (casi 5 veces más 
que los nativos no migrantes) cuando se analiza el segundo de estos problemas de empleo. Ello es particularmente grave si se tiene en cuenta que una inserción precaria a la llegada a un país extranjero limita las oportunidades futuras de movilidad laboral y social ascendente. Además, si bien el tiempo mitiga la magnitud de este efecto no es nada despreciable el riesgo de sobrecalificación encontrado para los inmigrantes más antiguos.

A diferencia de los resultados encontrados para el acceso al empleo y la informalidad, la sobrecalificación no parece ser una problemática de empleo que tenga un comportamiento diferencial por sexo entre los inmigrantes, pues el efecto positivo de ser mujer no varía según condición migratoria (modelo 3, tabla 4) u origen nacional de los inmigrantes (modelo 4, tabla 4).

Tabla 4 - Resultados de modelo logístico binomial para la probabilidad de estar sobrecalificado en el empleo. Uruguay, 2012-2014

\begin{tabular}{|c|c|c|c|c|}
\hline & 1 & 2 & 3 & 4 \\
\hline Mujer (ref. varón) & $0.947^{* * *}$ & $0.939 *$ & $0.934^{*}$ & $0.929 *$ \\
\hline E.S. & 0.033 & 0.033 & 0.033 & 0.033 \\
\hline Edad & $1.045^{* * *}$ & $1.046 * * *$ & $1.045^{* * *}$ & $1.046^{* * *}$ \\
\hline E.S. & 0.006 & 0.007 & 0.006 & 0.006 \\
\hline Edad*Edad & $0.999 * * *$ & $0.999 * * *$ & $0.999 * * *$ & $0.999 * * *$ \\
\hline E.S. & 0.000 & 0.000 & 0.000 & 0.000 \\
\hline \multicolumn{5}{|l|}{$\begin{array}{l}\text { Condición migratoria (ref. No } \\
\text { migrante) }\end{array}$} \\
\hline Inmigrante reciente & $4.925 * * *$ & $5.780 * * *$ & $4.345^{* * *}$ & $5.686^{* * *}$ \\
\hline the & 0.770 & 1.731 & 0.834 & 1.979 \\
\hline Inmigrante antiguo & $1.891^{* * *}$ & $2.552 * * *$ & $1.738^{* * *}$ & $2.579 * *$ \\
\hline E.S. & 0.168 & 0.672 & 0.190 & 0.770 \\
\hline Retornado reciente & 1.165 & & 1.189 & \\
\hline E.S. & 0.147 & & 0.172 & \\
\hline Retornado antiguo & $1.599 * * *$ & & $1.508^{* * *}$ & \\
\hline & 0.142 & & 0.161 & \\
\hline \multicolumn{5}{|l|}{ Lugar nacimiento (ref. resto mundo) } \\
\hline España & & 0.564 & & 0.609 \\
\hline E.S. & & 0.245 & & 0.310 \\
\hline Estados Unidos & & 1.505 & & 0.800 \\
\hline E.S. & & 1.059 & & 0.715 \\
\hline Argentina & & 0.604 & & $0.500^{*}$ \\
\hline E.S. & & 0.172 & & 0.165 \\
\hline Brasil & & 0.750 & & 0.698 \\
\hline E.S. & & 0.234 & & 0.251 \\
\hline Nuevos orígenes LAC & & 1.319 & & 1.295 \\
\hline E.S. & & 0.414 & & 0.472 \\
\hline \multicolumn{5}{|l|}{ Categoría ocupación (ref. asalariado) } \\
\hline Independiente sin local & $0.344 * * *$ & $0.342^{* * *}$ & $0.344^{* * *}$ & $0.340 * * *$ \\
\hline E.S. & 0.046 & 0.046 & 0.046 & 0.046 \\
\hline Independiente con local & 0.984 & 0.977 & 0.984 & 0.976 \\
\hline 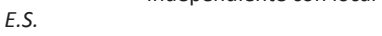 & 0.039 & 0.039 & 0.038 & 0.039 \\
\hline Patrón/cooperativista & $1.991 * * *$ & $2.011^{* * *}$ & $1.992 * * *$ & $2.009 * * *$ \\
\hline E.S. & 0.119 & 0.122 & 0.119 & 0.122 \\
\hline \multicolumn{5}{|l|}{ Cualificación (ref. ninguna) } \\
\hline Manual & 0.963 & 0.953 & 0.963 & 0.952 \\
\hline \multirow[b]{2}{*}{ Baja cualificación / No manual } & 0.03 & 0.033 & 0.033 & 0.033 \\
\hline & $1.298 * * *$ & $1.305 * * *$ & $1.297^{* * *}$ & $1.304^{* * *}$ \\
\hline E.S. & 0.049 & 0.049 & 0.048 & 0.049 \\
\hline Año 2012 & $0.850 * * *$ & $0.848 * * *$ & $0.850 * * *$ & $0.849 * * *$ \\
\hline E.S. & 0.030 & 0.031 & 0.031 & 0.031 \\
\hline Año 2013 & $0.895^{*}$ & $0.901^{* *}$ & $0.895 * *$ & $0.900 * *$ \\
\hline E.S. & 0.031 & 0.031 & 0.031 & 0.032 \\
\hline Mujer*Inmigrante reciente & & & 1.447 & 1.035 \\
\hline E.S. & & & 0.476 & 0.724 \\
\hline Mujer*Inmigrante antiguo & & & 1.296 & 0.959 \\
\hline
\end{tabular}




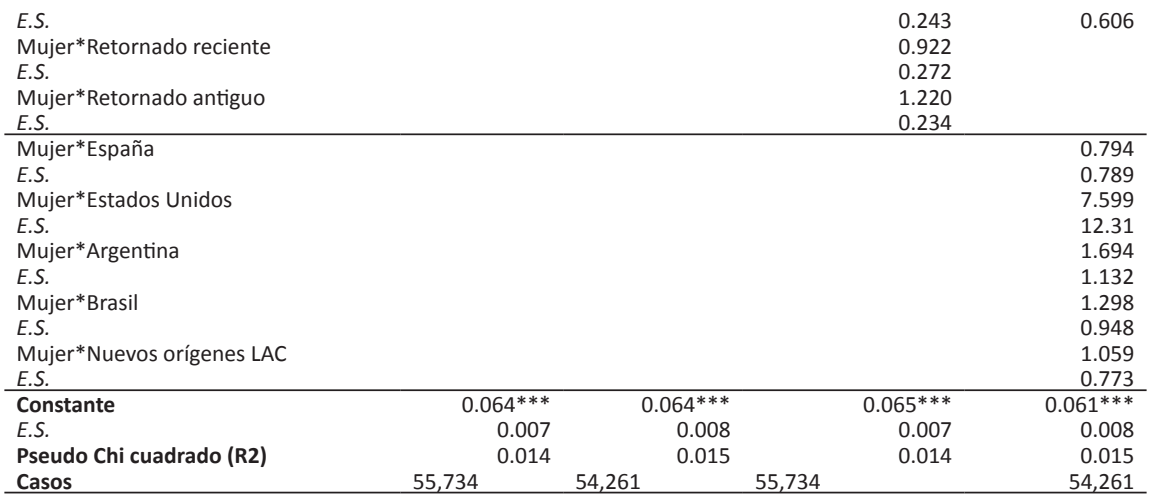

Nota: $* \mathrm{p}<0.05, * * 0.01, * * * 0.001$, E.S. error estándar. Los modelos 2 y 4 excluyen a la población retornada, y la categoría de "Alta cualificación/ No manual" fue expulsada de estas estimaciones por colinearidad. Este grupo de modelos excluye a los ocupados subcalificados.

\section{Discusión y conclusiones}

Hasta aquí se han descrito las características de la inserción laboral de los inmigrantes recientes, retornados y extranjeros, con especial énfasis en los segundos. El período analizado, recorre los últimos cinco años, que coinciden con la aprobación de una legislación migratoria amigable al asentamiento de extranjeros, con el relativo crecimiento del empleo, con cierta reducción de las fracturas del mercado laboral, y con la diversificación de orígenes de la inmigración. Este contexto auguraría una inserción de calidad para la inmigración reciente pero los resultados aquí presentados contravienen esta intuición.

En primer término, y en coincidencia con la hipótesis que da pie a este trabajo, los inmigrantes extranjeros llegados recientemente enfrentan mayores dificultades de acceso al empleo que la población nativa no migrante con similares características de sexo, edad y educación. Además, sufren en mayor medida la informalidad y sobrecalificación del empleo.

Entre la población ocupada de origen extranjero se observa una concentración en puestos de media y alta cualificación. Este hecho sugeriría, a priori, que no habría competencia entre inmigrantes y nativos, aunque este aspecto merece un estudio específico donde se analicen las ocupaciones con mayor nivel de desagregación del aquí considerado y supone la necesidad de aplicar métodos de análisis de dispersión. La buena noticia de la complementariedad laboral entre inmigrantes y extranjeros, contrasta con que la informalidad y la sobrecalificación son más comunes entre los inmigrantes recientes que entre los más antiguos y los nativos. La probabilidad de los inmigrantes recientes de encontrarse en empleos que demandan un tipo de tareas no acordes a su formación es cinco veces superior a la de los uruguayos 
no migrantes, lo que convierte a este fenómeno en el principal problema de empleo que enfrenta la inmigración recién llegada.

Si bien la condición de inmigrante reciente reduce las probabilidades de inserción laboral exitosa, no se encontraron diferencias por origen nacional en el riesgo de sobrecalificación, aunque el país de nacimiento sí parece ser significativo para analizar desempeños diferenciales en cuanto a informalidad y empleo. Los inmigrantes brasileños y argentinos son los más perjudicados en el acceso al empleo. A su vez los estadounidenses y brasileños - dos orígenes cuyo idioma nativo no es el español- son los más afectados por la informalidad del empleo. Los nuevos orígenes latinoamericanos no se vieron particularmente afectados en relación a estos problemas de empleo ni en la búsqueda de empleo, aunque no se descarta que este resultado sea consecuencia del reducido número de caso de este origen que captan las $\mathrm{ECH}$. Puede concluirse entonces que no se encuentra un sesgo sistemático (en empleo, informalidad y sobrecalificación) del origen nacional que favorezca o perjudique a los inmigrantes de un origen en particular.

En cuanto al efecto del tiempo de asentamiento como mitigador de las dificultades que enfrentan los inmigrantes extranjeros en el mercado de trabajo, los resultados son ambiguos. Por un lado se corroboró que tras cierto tiempo de residencia en Uruguay la desventaja de la condición de inmigrante en el acceso al empleo respecto a la población nativa desaparece. Por otro lado, si bien la sobrecalificación y la informalidad también se atenúan con el tiempo de asentamiento, el riesgo de caer en estas dificultades no desaparece entre quienes llevan más de cinco años en el país y es siempre superior al de los nativos no migrantes. Algo similar ocurre entre los retornados, para los que vemos que el tiempo solo los protege frente al desempleo pero no diluye el riesgo de sobrecalificación o la informalidad. Estos resultados abren la siguiente interrogante: ¿Existe un efecto de discriminación hacia el extranjero y el retornado, o solo es cuestión de tiempo para que estas personas fortalezcan sus redes sociales, acumulen saberes y experiencias locales, y/o o convaliden sus titulaciones? Puede pensarse también que la precariedad laboral se asocia a estrategias de aceptación de trabajos como puerta de entrada a la inserción en un contexto nuevo y que con el paso del tiempo esta situación-como de hecho se observa- tiende a evitarse. En cualquier caso, debe advertirse que los niveles de desafiliación laboral de los inmigrantes más antiguos y recientes, se traducen en un mayor riesgo de desafiliación a los servicios de salud en Uruguay y comprometen las oportunidades de movilidad sociolaboral posterior.

Finalmente, este artículo también ha intentado contrastar si existe un efecto diferencial del estatus migratorio según sexo. Efectivamente, las mujeres inmigrantes tienen siempre peores desempeños que sus pares varones en el acceso al empleo, pero la doble condición de mujer e inmigrante no representa 
una doble desventaja en el análisis de la sobrecalificación e incluso las mujeres migrantes se ven favorecidas respecto a los varones frente al riesgo de estar ocupadas sin realizar aportes. Entonces, puede interpretarse que una vez que las mujeres inmigrantes superan las dificultades de acceso al mercado de trabajo consiguen mejores condiciones laborales que los varones de igual origen.

En futuros análisis sería pertinente indagar si existe un efecto diferencial de la condición migratoria sobre el acceso y la calidad del empleo según el nivel de instrucción. En función de las dificultades que suelen encontrar los inmigrantes para revalidar sus credenciales educativas o lograr el reconocimiento de las competencias laborales adquiridas en el exterior, es factible suponer, como se ha comprobado para el caso de la inmigración extranjera intra-regional en Argentina $^{36}$ y la migración de retorno en Uruguay ${ }^{37}$, que la brecha entre los inmigrantes recientes y la población sin experiencia migratoria se acentúe en la población con estudios superiores completos y se mitigue en las personas con bajo nivel de instrucción. De modo similar, también resulta de interés incorporar el estudio de las diferencias salariales entre inmigrantes y nativos, así como la perspectiva cualitativa de los propios inmigrantes y empleadores, con el fin de examinar, entre otros asuntos, en qué medida y bajo qué condiciones el capital humano adquirido en el exterior es valorado por el mercado de trabajo nacional.

\section{Referencias}

AGEV. Reporte Social 2013. Principales características del Uruguay social. Montevideo: AGEV-OPP, 2013.

AMARANTE, Verónica; PERAZZO, Ivonne. Trabajo por cuenta propia y monotributo en Uruguay. Revista internacional del trabajo, v. 132, diciembre 2013, p. 623-641.

AYSA-LASTRA, María; CACHÓN, Lorenzo. Latino Immigrant Employment During the Great Recession: A Comparison of the United States and Spain. Norteamérica, v. 7, n. 2, julio-diciembre 2012, p. 7-42.

BENGOCHEA, Julieta. Inmigración reciente en Uruguay: 2005-2011. Universidad de la República. 2014. Tesis de maestría en Demografía y Estudios de Población. Disponible en: <http://cienciassociales.edu.uy/unidadmultidisciplinaria/wpcontent/uploads/sites/6/2015/10/Tesis-Maestr\%C3\%ADa-N\%C2\%BA1-1.pdf >. Acceso en: 04.04.2016.

BERGER, Suzanne; PIORE, Michael (eds.). Dualism and Discontinuity in Industrial Society. New England: Cambridge, 1980.

BERNARDI, Fabricio; GARRIDO, Luis; MIYAR, María. The Recent Fast Upsurge of Immigrants in Spain and Their Employment Patterns and Occupational Attainment. International Migration, v. 49, n. 1, febrero 2011, p. 148-187.

\footnotetext{
${ }^{36}$ CERRUTTI, Marcela, MAGUID, Alicia. Inserción laboral e ingresos de los migrantes de países limítrofes y peruanos en el gran Buenos Aires.

37 KOOLHAAS, op. cit.; PRIETO, op. cit.
} 
CERRUTTI, Marcela. Diagnóstico de las poblaciones de inmigrantes en la Argentina. 2009. Dirección Nacional de Población. Disponible en: <http:// www.mininterior.gov.ar/poblacion/pdf/Diagnostico_de_las_poblaciones_de_ inmigrantes_en_Argentina.pdf >. Acceso en: 10.04.2016.

CERRUTTI, Marcela; MAGUID, Alicia. Inserción laboral e ingresos de los migrantes de países limítrofes y peruanos en el gran Buenos Aires. Notas de Población, v. 83, 2007, p. 75-98.

ESPINO, Alma; MACHADO, Alina; ALVES, Guillermo. Estudio de las tendencias cuantitativas y cualitativas de la oferta laboral. Documento de Trabajo 6/11. 2011. lecon. Disponible en: <http://www.bcu.gub.uy/Estadisticas-e-Indicadores/ Documentos\%20de\%20Trabajo/7.2011.pdf > . Acceso en: 02.04.2016.

GAINZA, Patricia. Hablando de derechos. Pensando en derechos humanos. Montevideo: MIDES, 2012.

GANDINI, Luciana; LOZANO, Fernando. The Effects of the Crisis on Occupational Segregation of Skilled Migrants from Latin America and the Caribbean in the United States, 2006-2012. Population, Space and Place, 2015. Disponible en: <http://doi.wiley.com/10.1002/psp.1909>. Acceso en: 04.04. 2016.

HERRERA, Gioconda. Género y migración internacional en la experiencia latinoamericana. De la visibilización del campo a una presencia selectiva. Política y Sociedad, v. 49, n. 1, 2012, p. 35-46.

HERRERA. Gioconda. Starting Over Again? Crisis, Gender, and Social Reproduction among Ecuadorian Migrants in Spain. Feminist Economics, v. 18, n. 2, Julio 2012, p. 125-148.

KOOLHAAS, Martín. Migración internacional de retorno en Uruguay : magnitud, selectividad y reinserción laboral en tiempos de crisis económica internacional. Tesis de Maestría en Demografía y Estudios de Población. Universidad de la República, 2015. Disponible en: $<$ http://cienciassociales.edu.uy/unidadmultidisciplinaria/ wp-content/uploads/sites/6/2015/10/Tesis-Maestr-\%C2\%A1a-N-\%C2\%A65. pdf>. Acceso en: 04.04.2016.

KOOLHAAS, Martín; NATHAN, Matías. Inmigrantes internacionales y retornados en Uruguay: magnitud y características. Informe de resultados del Censo de Población 2011. Montevideo: INE, 2013.

MAGUID, Alicia; BRUNO, Sebastián. Migración, mercado de trabajo y movilidad ocupacional: el caso de los bolivianos y paraguayos en el Área Metropolitana de Buenos Aires. Población de Buenos Aires, v. 7, n. 12, octubre 2010, p. 7-28.

MARTINEZ-PIZZARRO, Jorge; RIVERA-ORREGO, Cristina. Nuevas tendencias y dinámicas migratorias en América Latina y el Caribe. Santiago de Chile: CEPAL, 2016.

OECD; OEA. Tercer Informe del Sistema Continuo de Reportes sobre Migración Internacional en las Américas (SICREMI). Washington DC: OEA, 2015.

OIT. Panorama Laboral Temático. Transición a la formalidad en América Latina y el Caribe. Lima. 2014. Disponible en: <http://www.ilo.org/wcmsp5/groups/ public/---americas/---ro-lima/documents/publication/wcms_315054.pdf > . Acceso en: 06.04.2016. 
PELLEGRINO, Adela. Migraciones. Montevideo: Colección nuestra Tierra MEC, 2014. PORTES, Alejandro. Introduction: Immigration and Its Aftermath. International Migration Review, v. 28, n. 4, 1994, p. 632-639.

PRIETO, Victoria. Las consecuencias de quedarse y de volver en el empleo de los uruguayos que migraron a España. Notas de Población, n. 102, 2016, p. 149-177.

PROGRAMA DE POBLACIÓN - MIDES. Integración de la población extranjera y retornada en Uruguay (documento inédito). Montevideo, 2016. EN PRENSA.

SALA, Gabriela. Sobrecalificación de los migrantes del Cono Sur residentes en Argentina y Brasil. Migraciones internacionales, v. 5, n. 2, julio-diciembre 2009, p. 122-152.

STEFONI, Carolina. Mujeres inmigrantes peruanas en Chile. Papeles de Población, v. 8, n. 33, 2002, p. 117- 144.

SPARREBOOM, Theo; STANEVA, Anita. Is education the solution to decent work for youth in developing economies? Youth Publication Series, n. 23, 2014. Disponible en: <http://www.un.org/youthenvoy/wp-content/uploads/2014/10/ Work4Youth-Publication.pdf >. Acceso en: 02.05.2016.

TORRES, Eduardo; CELTON, Dora. Discriminación salarial en Argentina entre nativos y paraguayos. Cuadernos Geográficos, n. 45, 2009, p. 263-285.

VIDAL, Elena; GIL, Fernando; ANDREU, Domingo. La población femenina extracomunitaria en España. Análisis territorial de los factores de inserción laboral. Papers de demografia, n. 47-48, enero-diciembre 2008, p. 193-213.

VIDAL, Elena; VONO, Daniela. La inserción de las mujeres inmigradas en el mercado de trabajo español. Documents d'Analisi Ceografica, v. 57, n. 3, 2011, p. 563-573.

VIDAL-COSO, Elena; MIRET-GAMUNDI, Pau. The labour trajectories of immigrant women in Spain: Are there signs of upward social mobility? Demographic Research, v. 3, n. 1, agosto 2014, p. 337-380.

VONO, Daniela. ¿Preferidos Y Favorecidos? (Tesis doctoral inédita). Universitat Autónoma de Barcelona. 2010. Disponible en: <http://www.tdx.cat/bitstream/ handle/10803/32142/dvv1de1. pdf; jsessionid=7DBB91E52417F1A3F9D302AF 05B1EFDE.tdx1? sequence=1>. Acceso en: 04.04.2016.

Recibido para publicación en 21.06.2016

Aceptado para publicación en 20.09.2016

Received for publication in June 215t, 2016

Accepted for publication in September 20, 2016

ISSN impresso 1980-8585

ISSN eletrônico 2237-9843

http://dx.doi.org/10.1590/1980-85852503880004809 